\title{
How similar are human emotions to those of other vertebrates, and how do emotions help organize thought, action and social life?
}

\author{
Egbert Giles Leigh Jr. ${ }^{*}$ (])
}

\begin{abstract}
This is a review of de Waal's Mama's Last Hug, which shows how similar human emotions are to those of other social vertebrates, and how emotions shape thought, action and social life.

Keywords: Chimpanzee sociality, Emotions, functions of, Emotions, similarity between humans and other social mammals, Empathy, Sympathy, Interdependence and sociality
\end{abstract}

\section{Book details \\ Frans de Waal}

Mama's Last Hug: Animal Emotions and What They Tell Us About Ourselves

New York: W. W. Norton. 2019

Pp. $x+326$. ISBN 978-0-393-63506-5. H/b \$27.95

\section{Book review}

In this book, Frans de Waal has two major objectives. First, he seeks to show how very similar the human spectrum of emotions (and our ways of dealing with them) are to those of chimpanzees, and to a lesser extent, those of other social vertebrates, particularly capuchin monkeys, elephants, dogs and rats. Second, he seeks to demonstrate the adaptive value of these emotions-in responding to crises, maintaining social cohesion and social order, and even in reasoning effectively. He also shows how their similarity to human emotions reveals how much suffering industrial agriculture, as opposed to traditional small-holder agriculture, imposes on the cows, pigs and

*Correspondence: bufotyphonius@gmail.com Baltimore, MD, USA chickens it "produces." Here, ignorance and economic determinism have perverted how farmers treat the animals we depend on for food.

In this attractively written book, De Waal (p. 1) focuses on the relationship between emotional expressions, body language, and social dynamics. Darwin (1872) showed that the same emotion produces the same facial expression in people of all races, and usually produces similar facial expressions in other social mammals, especially monkeys and apes. Thus, even when studying human beings, de Waal (p. 5) prefers observation and controlled experiment to questionnaires. He expresses one crucial key to his methodology (p. 197) as: "I consider empathy my bread and butter, as I have made many a discovery by getting under the skin of my subjects." Similarly, G. K. Chesterton (1981, p. 465) has his fictitious detective Father Brown remark that instead of "getting outside a man and studying him as if he were a gigantic insect, in what they would call a dry impartial light, in what I should call a dead, dehumanizing light. I try to get inside the murderer. I am always inside a man, moving his arms and legs, but I wait until I am inside a murderer, thinking his thoughts, wrestling with his passions."

De Waal's (pp. 13-19) title scene concerns his dissertation professor's last visit to a dying chimpanzee, Mama, whom he had known for 40 years. She was the

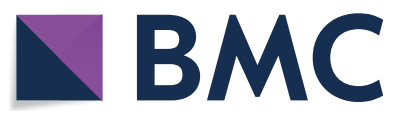

(c) The Author(s) 2019. This article is licensed under a Creative Commons Attribution 4.0 International License, which permits use, sharing, adaptation, distribution and reproduction in any medium or format, as long as you give appropriate credit to the original author(s) and the source, provide a link to the Creative Commons licence, and indicate if changes were made. The images or other third party material in this article are included in the article's Creative Commons licence, unless indicated otherwise in a credit line to the material. If material is not included in the article's Creative Commons licence and your intended use is not permitted by statutory regulation or exceeds the permitted use, you will need to obtain permission directly from the copyright holder. To view a copy of this licence, visit http://creativeco mmons.org/licenses/by/4.0/. The Creative Commons Public Domain Dedication waiver (http://creativecommons.org/publicdomain/ zero/1.0/) applies to the data made available in this article, unless otherwise stated in a credit line to the data. 
matriarch of her zoo's chimp colony. When he entered her night cage and she recognized him, they embraced each other: she used typically human gestures to assure him of his welcome in her cage and her delight in his visit. When a video of the scene appeared on Dutch television, viewers were deeply moved (p. 16). De Waal (pp. 21-30) then described her role in maintaining her colony's cohesion-reconciling quarreling males, preventing disruptive behavior by the dominant male, etc. Her role required both forcefulness and extraordinary diplomatic ability, which presupposes insight into the motives and feelings of her fellows and the skills to use this insight to maintain peace. This description seems grossly anthropomorphic, it invokes such human attributes, but de Waal (pp. 47-51) argues convincingly that the close evolutionary relationship between human beings and chimpanzees, and the similarity in expression of their emotions, allows us to recognize their emotions the same way we recognize our own. Refusal to benefit from this similarity denies us an essential tool for understanding their behavior, and presumes an unjustifiably large gap between ourselves and our closest evolutionary relatives.

Our various emotions are as essential to us as our physiological organs (p. 166). A cluster of emotions, including love and attachment (p. 166), essential to maintaining the cooperation that enables social life (Darwin 1871, vol. I chapter 3), are based on sympathy (p. 105). Sympathy presupposes empathy, the ability to sense how a companion would respond to a given circumstance, painful or pleasant (p. 106). Empathy in turn presupposes sentience that can experience and remember subjective feelings of pain or pleasure associated with different happenings (p. 248). Empathy, however, can enable refined cruelty, whereas sympathy reflects concern and willingness to help (p. 107). De Waal (1996) has demonstrated sympathy in many kinds of animals. Sympathy is best developed in groups whose members' survival depends on each other's cooperation (Darwin 1871, pp. 78-79), as in hunter-gatherer groups, wolf packs, troops of capuchin monkeys (p. 176, Crofoot et al. 2008), or Plato's gang of thieves, who must treat each other fairly to ensure the cooperation needed for the thieves to survive (Plato, Republic, Book I, 351c). In accord with sympathy's small-group origins, one is most likely to be sympathetic to a neighbor: being very close to a sufferer enhances sympathy (p. 92). Such sympathy is revealed in various ways. Human and chimpanzee infants (pp. 99, 101) and adult elephants (p. 241), try to comfort a distressed companion: babies as young as 19 months do so (Changeux and Ricoeur 2000, p. 156). Simply holding hands with a spouse or friend reduces fear in a person under stress (p. 233). In what seems to be a show of sympathy with a master whose leg is broken, his dog may feign a broken leg until the master recovers (p. 93).
An interdependent group needs mutual sympathy to maintain cohesion. Many other emotions, however, enable a group's function, as long as they are kept in proper relationship with each other, Envy, as reflected in a capuchin's furious refusal to accept a lesser reward than he has seen a companion receive for the same task (p. 209) helps equalize food distribution in the group, giving all a more nearly equal stake in the group's survival (p. 219). Chimpanzees have an ampler concept of fairness. Dominant males will break up disputes over food without taking any, and ensure that the subordinates share the disputed food (p. 215). Alpha males that play favorites in this function risk being replaced by more impartial peace-makers (de Waal 1996, p. 130). Gratitude, which caused a chimp with poor lactation to befriend de Waal for the rest of her life after he taught her to bottle-feed her young, enabling them to survive (p. 26), rewards cooperative behavior. Similarly, chimps regularly give food to those who have given them food in the past but not to those who refuse to share (p. 130). Expressing guilt or shame reveals a deep desire to remain a member of the group (p. 154). Indeed, experiments show that a dog's demeanor of shame is independent of any past wrongdoing, and is simply meant to appease an angry master. Anger and aggression are social emotions, which help maintain the hierarchy underlying the group's social order (p. 190). Nonetheless, reconciliation after disputes, often approved or even demanded by the rest of the group (de Waal 1996, p. 205), is needed to limit collateral damage from the dispute (p. 134). Emotion is an essential motivation for sound reasoning (p. 209): one cannot make rational choices when unable to remember in the light of past memories how satisfactory their outcomes will be (Changeux and Ricoeur 2000: pp. 196-197). Facial expressions tend to be honest signals of emotions (pp. 67-68): it is easy to distinguish a faked smile (p. 67).

Emotions, however, must be kept in appropriate relationship to each other. If a subordinate male chimp tries to mate with a receptive female within sight of the alpha male, the subordinate will be thrashed (pp. 223-224): here, fear should trump lust. Similarly, a chimpanzee will wait to take revenge on another until the other is isolated from its allies (p. 35). Apes will forgo a juicy grape in favor of a tool that can be used hours later to secure a much greater reward (p. 136). If free will is the ability to choose between different desires, then chimpanzees have it, and so do many other vertebrates. A rat given a choice between eating and liberating a trapped companion will often first free the companion (p. 118). This raises the question: how does an animal learn to manage its emotions (p. 236), that is to say, to free its will? They can only do so in the context of social life. In a sanctuary for infant bonobos rescued from poachers, the few 
bonobos born in the sanctuary and raised by their mothers reacted much less strongly to rebuffs or bites from companions and were far more likely to comfort others in distress than orphaned bonobos. Play is an especially effective school for managing emotions. Play is initiated by a specific gesture, such as a dog's play-bow, signifying good intentions (p. 71). A primary rule of play is not to inflict serious pain during a play-fight (Huizinga 1950, p. 1 ). And indeed, successful play, especially in competitive games, requires emotional self-control (de Waal 1996, p. 118).

De Waal draws a forceful lesson from his comparison of emotions in man and other animals. Social life in animals hinges on empathy, which hinges on a sentience that must in turn depend on consciousness, which remembers, evaluates, and causally connects past events and feelings (p. 255). How could one dispute his conclusion that industrial agriculture is intensely cruel to cows, pigs and chickens (all social animals), far more so than traditional smallholder agriculture ever was (pp. 242-243)? After all, a small-holder's animals are likely to be his companions, whom he knows by name, and on whom he may depend in various rather immediate ways. Voltaire put a question to vivisectors (Midgley 1983, p. 11):-“You discover [in the animal] all the same organs of feeling that are in yourself. Answer me, mechanist, has nature arranged all the means of feeling in the animal so that it may not feel?" Indeed, since the physiology of Voltaire's day has been supplemented by many other lines of evidence, much of it discussed in Mama's Last Hug, the question can be put even more forcefully to industrial agriculturalists. The toxic mix of so emphasizing the gap between man and other animals that allows many to view other animals as unfeeling Cartesian machines (Midgley 1983 , p. 11), and isolation of decision-makers from the animals whose fates they decide, is a bit too like the isolation of the bomber pilot from the victims of his bombs. This mix has been worse for industrial farm animals than eugenics for human beings. Mama's Last Hug gives us plenty to think about, but is also a call to action on behalf of the animals reared by industrial farms.

\section{Acknowledgements}

The author is most grateful to Revati Gireesh for her guidance through the process of electronic submission.

\section{Authors' contributions}

EGL read the book and wrote the book review. The author read and approved the final manuscript.

Funding

The author received no funding for preparing this book review.

Availability of data and materials

Not applicable.

Competing interests

The author declares no competing interests.

Received: 18 November 2019 Accepted: 11 December 2019 Published online: 20 December 2019

\section{References}

Changeux J-P, Ricoeur P. What makes us think?. Princeton: Princeton University Press; 2000.

Chesterton GK. The Penguin complete Father Brown. Harmondsworth: Penguin Books; 1981.

Crofoot MC, Gilby IC, Wikelski MC, Kays RW. Interaction location outweighs the competitive advantage of numerical superiority in Cebus intergroup contests. PNAS. 2008;105:577-81.

Darwin C. The descent of man, and selection in relation to sex. London: John Murray; 1871.

Darwin C. The expression of the emotions in man and animals. London: John Murray; 1872.

De Waal FBM. Good natured: the origins of right and wrong in humans and other animals. Cambridge: Harvard University Press; 1996.

Huizinga J. Homo Ludens: a study in the play element of culture. New York: Roy Publishers; 1950.

Midgley M. Animals and why they matter. Athens: University of Georgia Press; 1983.

\section{Publisher's Note}

Springer Nature remains neutral with regard to jurisdictional claims in published maps and institutional affiliations. 